\title{
Reviews and Syntheses: Responses of coccolithophores to ocean acidification: a meta-analysis
}

\author{
J. Meyer and U. Riebesell \\ GEOMAR Helmholtz Centre for Ocean Research Kiel, Kiel, Germany \\ Correspondence to: J. Meyer (jumeyer@geomar.de)
}

Received: 16 September 2014 - Published in Biogeosciences Discuss.: 22 October 2014

Revised: 4 February 2015 - Accepted: 17 February 2015 - Published: 16 March 2015

\begin{abstract}
Concerning their sensitivity to ocean acidification, coccolithophores, a group of calcifying single-celled phytoplankton, are one of the best-studied groups of marine organisms. However, in spite of the large number of studies investigating coccolithophore physiological responses to ocean acidification, uncertainties still remain due to variable and partly contradictory results. In the present study we have used all existing data in a meta-analysis to estimate the effect size of future $p \mathrm{CO}_{2}$ changes on the rates of calcification and photosynthesis and the ratio of particulate inorganic to organic carbon (PIC / POC) in different coccolithophore species. Our results indicate that ocean acidification has a negative effect on calcification and the cellular PIC / POC ratio in the two most abundant coccolithophore species: Emiliania huxleyi and Gephyrocapsa oceanica. In contrast, the more heavily calcified species Coccolithus braarudii did not show a distinct response when exposed to elevated $p \mathrm{CO}_{2} /$ reduced $\mathrm{pH}$. Photosynthesis in Gephyrocapsa oceanica was positively affected by high $\mathrm{CO}_{2}$, while no effect was observed for the other coccolithophore species. There was no indication that the method of carbonate chemistry manipulation was responsible for the inconsistent results regarding observed responses in calcification and the PIC / POC ratio. The perturbation method, however, appears to affect photosynthesis, as responses varied significantly between total alkalinity (TA) and dissolved inorganic carbon (DIC) manipulations. These results emphasize that coccolithophore species respond differently to ocean acidification, both in terms of calcification and photosynthesis. Where negative effects occur, they become evident at $\mathrm{CO}_{2}$ levels in the range projected for this century in the case of unabated $\mathrm{CO}_{2}$ emissions. As the data sets used in this meta-analysis do not account for adaptive responses, ecological fitness and ecosystem inter-
\end{abstract}

actions, the question remains as to how these physiological responses play out in the natural environment.

\section{Introduction}

Coccolithophores, a globally distributed group of marine haptophytes, are major primary producers in the ocean and the most prolific calcifying organisms on our planet (Brownlee and Taylor, 2004; Shutler et al., 2010). By performing photosynthesis and calcification, they contribute to both biological carbon pumps - the soft tissue pump and the carbonate-counter pump. While the former supports carbon sequestration in the ocean through production and sinking of organic matter to depth, the latter decreases the ocean's capacity to take up $\mathrm{CO}_{2}$ due to the reduction in surface layer alkalinity. Moreover, by providing ballast material, which accelerates sinking velocities of organic particles to depth, coccolithophore-derived calcite contributes to enhancing carbon sequestration to depth (Klaas and Archer, 2002; Armstrong et al., 2002; Ziveri et al., 2007). Thus, changes in the contribution of coccolithophores to ocean primary production could potentially impact global carbon cycling (Riebesell et al., 2009).

In the face of global change, phytoplankton are subjected to rapid alterations in their environmental conditions. Due to the sensitivity of calcification to ocean acidification, coccolithophores are considered to be among those which may be adversely affected in a high- $\mathrm{CO}_{2}$ future ocean. While impacts of ocean acidification on coccolithophores have been studied extensively (for a review see, for example, Riebesell and Tortell, 2011), variable and partly conflicting responses were observed in different perturbation studies (for a sum- 
Table 1. Summary of the available carbonate chemistry manipulation experiments and the responses of Emiliania huxleyi as reported by the authors of those studies. Symbols: - no response; / increased response; $\cap$ nonlinear response; $\backslash$ decreased response.

\begin{tabular}{|c|c|c|c|c|c|c|c|}
\hline Reference & $\begin{array}{l}\text { E. huxleyi } \\
\text { strain }\end{array}$ & $\begin{array}{l}\text { Experiment } \\
\text { type }\end{array}$ & $\begin{array}{l}\mathrm{CO}_{2} \\
\text { manipulation }\end{array}$ & $\begin{array}{c}\text { PIC } \\
\text { production }\end{array}$ & $\begin{array}{c}\mathrm{POC} \\
\text { production }\end{array}$ & $\mathrm{PIC} / \mathrm{POC}$ & Specifics \\
\hline Bach et al. (2011) & PML B92/11A & laboratory & constant DIC & $\cap$ & 1 & 1 & large $p \mathrm{CO}_{2}$ range \\
\hline $\begin{array}{l}\text { Barcelos e } \\
\text { Ramos et al. (2010) }\end{array}$ & $\begin{array}{l}\text { Raune Fjord, } \\
\text { Norway, } 2005\end{array}$ & laboratory & constant DIC & 1 & / & 1 & $\begin{array}{l}\text { short-term } \\
\text { incubation }\end{array}$ \\
\hline De Bodt et al. (2010) & $\mathrm{AC} 481$ & laboratory & constant TA & 1 & - & 1 & $\begin{array}{l}\text { variable } \\
\text { temperatures }\end{array}$ \\
\hline Delille et al. (2005) & $\begin{array}{l}\text { Raune Fjord, } \\
\text { Norway, } 2001\end{array}$ & mesocosm & constant TA & 1 & - & 1 & \\
\hline Engel et al. (2005) & $\begin{array}{l}\text { Raune Fjord, } \\
\text { Norway, } 2001\end{array}$ & mesocosm & constant TA & 1 & - & 1 & \\
\hline Feng et al. (2008) & CCMP 371 & laboratory & constant TA & 1 & - & 1 & $\begin{array}{l}\text { variable light } \\
\text { and temperature }\end{array}$ \\
\hline Fiorini et al. (2011) & AC472 & laboratory & constant TA & / & - & / & \\
\hline Gao et al. (2009) & CS369 & laboratory & constant TA & 1 & $\cap$ & 1 & PAR and UVR \\
\hline Hoppe et al. (2011) & RCC1256 & laboratory & $\begin{array}{l}\text { constant DIC } \\
\text { and constant TA }\end{array}$ & 1 & - & 1 & \\
\hline Hoppe et al. (2011) & NZEH & laboratory & $\begin{array}{l}\text { constant DIC } \\
\text { and constant TA }\end{array}$ & 1 & / & 1 & \\
\hline $\begin{array}{l}\text { Iglesias- } \\
\text { Rodriguez et al. (2008) }\end{array}$ & NZEH & laboratory & constant TA & / & / & - & \\
\hline Langer et al. (2009) & RCC1212 & laboratory & constant TA & 1 & 1 & 1 & \\
\hline Langer et al. (2009) & RCC1216 & laboratory & constant TA & 1 & 1 & 1 & \\
\hline Langer et al. (2009) & RCC1238 & laboratory & constant TA & - & $\cap$ & - & \\
\hline Langer et al. (2009) & $\mathrm{RCC} 1256$ & laboratory & constant TA & $\cap$ & $\cap$ & - & \\
\hline Müller et al. (2010) & $\begin{array}{l}\text { Raune Fjord, } \\
\text { Norway, } 2005\end{array}$ & laboratory & constant DIC & 1 & - & 1 & $\begin{array}{l}\text { long-term } \\
\text { incubation }\end{array}$ \\
\hline Riebesell et al. (2000) & PML B92/11A & laboratory & constant DIC & 1 & / & 1 & $\begin{array}{l}\text { variable day } \\
\text { lengths and } \\
\text { light intensity }\end{array}$ \\
\hline Richier et al. (2011) & RCC1216 & laboratory & constant TA & - & - & - & \\
\hline $\begin{array}{l}\text { Rokitta and } \\
\text { Rost (2012) }\end{array}$ & RCC1216 & laboratory & constant TA & 1 & / & 1 & $\begin{array}{l}\text { low and high } \\
\text { light conditions }\end{array}$ \\
\hline Sciandra et al. (2003) & TW1 & laboratory & constant TA & $\backslash$ & 1 & - & chemostat \\
\hline Shi et al. (2009) & NZEH & laboratory & constant TA & 1 & 1 & 1 & \\
\hline Shi et al. (2009) & NZEH & laboratory & constant DIC & i & / & 1 & \\
\hline Zondervan et al. (2002) & PML B92/11A & laboratory & constant DIC & 1 & / & 1 & $\begin{array}{l}\text { variable day } \\
\text { lengths and } \\
\text { light intensity }\end{array}$ \\
\hline Wuori (2012) & CCMP 2668 & laboratory & constant TA & 1 & / & $\backslash$ & \\
\hline
\end{tabular}

mary see Tables 1 and 2). Differences in experimental conditions, such as in light intensity, temperature, salinity, nutrient concentration and $p \mathrm{CO}_{2}$ levels, have been attributed as possible causes for those variations. However, even studies with comparable experimental conditions have provided deviating responses of coccolithophores. Some of this divergence has been shown to be related to species- and strain-specific differences (Langer et al., 2006, 2009), but also the method of carbonate chemistry manipulation, whether through changes in total alkalinity (TA) or dissolved inorganic carbon (DIC), has been discussed as a possible cause of some of the observed discrepancies (Iglesias-Rodriguez et al., 2008; Shi et al., 2009).
Building on the extensive literature on coccolithophore responses to ocean acidification, the present study aims to provide statistically and methodologically robust estimates for those responses. In particular, we intend to answer the question of whether increasing seawater acidity alters calcification, photosynthesis and the PIC to POC ratio in acclimated cultures of coccolithophores. We further assess whether the observed responses are affected by the carbonate chemistry manipulation method and whether they differ between coccolithophore species, thus trying to address some of the inconsistencies in the existing studies. Recent meta-analyses conducted by Kroeker et al. $(2010,2013)$ and Hendriks et al. (2010) did not specifically focus on coccolithophores but analyzed responses of many different taxa to ocean 
Table 2. Summary of the available carbonate chemistry manipulation experiments and the responses of Coccolithus braarudii, Gephyrocapsa oceanica and Calcidiscus leptoporus found in those studies.

\begin{tabular}{|c|c|c|c|c|c|c|c|}
\hline Reference & Species & Strain & $\begin{array}{l}\text { Experiment } \\
\text { type }\end{array}$ & $\begin{array}{l}\mathrm{CO}_{2} \\
\text { manipulation }\end{array}$ & $\begin{array}{c}\text { PIC } \\
\text { production }\end{array}$ & $\begin{array}{c}\text { POC } \\
\text { production }\end{array}$ & PIC / POC \\
\hline Krug et al. (2011) & $\begin{array}{l}\text { Coccolithus } \\
\text { braarudii }\end{array}$ & RCC 1200 & laboratory & constant DIC & 1 & $\cap$ & 1 \\
\hline Langer et al. (2006) & & AC400 & laboratory & constant DIC & - & - & - \\
\hline Müller et al. (2010) & & RCC 1200 & laboratory & constant DIC & 1 & l & 1 \\
\hline Rickaby et al. (2010) & & 4762 & laboratory & constant DIC & j & 1 & - \\
\hline $\begin{array}{l}\text { Riebesell } \\
\text { et al. (2000) }\end{array}$ & $\begin{array}{l}\text { Gephyrocapsa } \\
\text { oceanica }\end{array}$ & $\mathrm{PC} 7 / 1$ & laboratory & constant DIC & 1 & / & 1 \\
\hline Rickaby et al. (2010) & & PZ 3.1 & laboratory & constant DIC & - & $\cap$ & 1 \\
\hline Fiorini et al. (2011) & $\begin{array}{l}\text { Calcidiscus } \\
\text { leptoporus }\end{array}$ & AC370 & laboratory & constant TA & - & - & - \\
\hline Langer et al. (2006) & & AC365 & laboratory & constant DIC & $\cap$ & - & $\cap$ \\
\hline $\begin{array}{l}\text { Langer and } \\
\text { Bode (2011) }\end{array}$ & & AC365 & laboratory & constant DIC & $\cap$ & - & $\cap$ \\
\hline
\end{tabular}

acidification. Although coccolithophores were included in those meta-analyses, only a few experiments (Kroeker et al., 2010: 13 experiments; Hendriks et al., 2010: 2 experiments for calcification responses, 12 experiments for photosynthetic responses; Kroeker et al., 2013: 19 experiments) were considered and no distinction was made between different coccolithophore species. The meta-analysis by Findlay et al. (2011) focused on Emiliania huxleyi, but only investigated the species' PIC / POC response to ocean acidification (15 experiments were included in the analysis). In our approach a larger set of experiments and response variables was analyzed, allowing for a more robust prediction of the impact of ocean acidification and related changes in seawater chemistry on coccolithophore physiological performance.

\section{Materials and methods}

\subsection{Literature search}

A literature search was conducted to compile a list of all published data sets on $\mathrm{CO}_{2} / \mathrm{pH}$ sensitivities of coccolithophore calcification and photosynthesis. As a first step the ISI database Web of Science (www.webofknowledge. com) was scanned for appropriate studies. Additional literature was obtained from the EPOCA (European Project on OCean Acidification) database (www.epoca-project.eu) and from the associated blog (www.oceanacidification. wordpress.com). Subsequently, the reference lists of all studies identified by this approach were scanned for other relevant literature.

Experimental data were extracted directly from the published papers or, if not reported therein, from the PANGEA ${ }^{\circledR}$ archive (www.pangaea.de). If the information could not be retrieved from either source, the first author of the study was contacted directly.

\subsection{Data selection}

All studies in which the carbonate system was altered and the effect on coccolithophores reported, comprising both laboratory and field experiments, were selected for this metaanalysis. Studies that varied other environmental factors in addition to seawater carbonate chemistry, such as light intensity, day length, temperature or nutrient availability, were also incorporated. Data of particulate inorganic (PIC) and organic carbon (POC) production rates, $\mathrm{pH}$ values, carbonate system parameters and experimental conditions (light level, day length, temperature, nutrients) were obtained for the control (ambient or preindustrial $p \mathrm{CO}_{2}$ level) and experimental treatments (elevated $p \mathrm{CO}_{2}$ level). If PIC and POC were provided as quota values on a per-cell basis, production rates were calculated by multiplying the growth rates $(\mu)$ by the cell quota of organic or inorganic carbon.

The following $p \mathrm{CO}_{2}$ levels were chosen to compare the responses of Emiliania huxleyi to preindustrial carbon dioxide concentrations of $\sim 280$ parts per million $(\mathrm{ppm})$ :

1. $\sim 380 \mathrm{ppm}-$ reflecting the present-day $p \mathrm{CO}_{2}$ level;

2. $\sim 780 \mathrm{ppm}-$ the $p \mathrm{CO}_{2}$ level projected for the end of this century under the SRES A1B scenario, IPCC Report 2000 (Nakicenovic et al., 2000);

3. $\sim 1000 \mathrm{ppm}-$ the $p \mathrm{CO}_{2}$ level projected for the end of the century under the "worst case" emission scenario A1FI, IPCC Report 2000 (Nakicenovic et al., 2000).

Since there was not a sufficient number of studies investigating the responses of Coccolithus braarudii and Gephyro- 
capsa oceanica at $p \mathrm{CO}_{2}$ levels around $780 \mathrm{ppm}$, only concentrations of $\sim 380$ and $\sim 1000 \mathrm{ppm}$ were used to compare the responses of these species. All experiments where the $p \mathrm{CO}_{2}$ levels deviated no more than $\pm 50 \mathrm{ppm}$ from the targeted $380 \mathrm{ppm}$ and no more than $\pm 100 \mathrm{ppm}$ from the targeted 780 and $1000 \mathrm{ppm}$ were included in the analysis. Since the studies by Lefebvre et al. (2012) and Jones et al. (2013) did not meet these specifications, they were excluded from the meta-analysis.

Manipulation of the seawater carbonate chemistry can be achieved in various ways. First, the carbonate system can be adjusted by bubbling with $\mathrm{CO}_{2}$. This approach increases $\left[\mathrm{CO}_{2}\right],\left[\mathrm{HCO}_{3}^{-}\right]$and DIC; decreases $\mathrm{pH}$ and $\left[\mathrm{CO}_{3}^{2-}\right]$; and does not change the alkalinity. Second, acid can be added, which increases $\left[\mathrm{CO}_{2}\right]$ and $\left[\mathrm{HCO}_{3}^{-}\right]$, decreases the alkalinity and $\left[\mathrm{CO}_{3}^{2-}\right]$, and does not change DIC. In both manipulations the saturation state $(\Omega)$ decreases as well. Although there are other ways to adjust the carbonate system, the above-mentioned methods are the ones most commonly used. Which manipulation method was applied to decrease the $\mathrm{pH}$ in each study was noted. Subsequently, a separate meta-analysis was conducted in order to analyze whether responses of coccolithophores varied between the methods. Here, only responses to a $p \mathrm{CO}_{2}$ elevation from preindustrial levels to 780 and $1000 \mathrm{ppm}$ were included in the analysis. On this basis, 22 experiments were excluded.

When studies reported results from multiple carbonate system perturbation experiments, all individual experiments were included in the analysis. The same applied when there were different experiments with various species or strains.

If not only the carbonate system but also other factors such as light intensity or day length were changed in a study, the approach of Kroeker et al. (2010) was adopted and the ambient level of the factor, defined by the authors of the primary study, was used to ensure the comparability between the experiments. If the observed responses of a study did not differ significantly for the ambient and non-ambient levels of a given environmental factor (always regarding the same $p \mathrm{CO}_{2}$ value), both experiments were included.

The data on PIC and POC production obtained by IglesiasRodriguez et al. (2008) were normalized to POC biomass following the approach suggested by Riebesell et al. (2008). Data shown in Table 1 represent the original measurements reported by Iglesias-Rodriguez et al. (2008) prior to normalization. Müller et al. (2010) did not report PIC and POC production rates in their study, since the sampling time for those data varied and created a bias in the data. By averaging the PIC and POC production rates over time, the bias was minimized and the data were suitable to be included in this metaanalysis.

\subsection{Data analysis}

Determining differences between the control and treatment groups in response to changes in carbonate chemistry was the first step in our analysis. For this purpose the logarithmically transformed response ratio $(L)$ was calculated for each experiment and response variable (PIC, POC and PIC / POC) as

$L=\ln (\mathrm{RR})=\ln \left(\bar{X}_{\mathrm{E}}\right)-\ln \left(\bar{X}_{\mathrm{C}}\right)$,

where $\bar{X}$ is the mean of a treatment (E) and a control (C) group. The response ratio is logarithmically transformed and unitless, thus allowing a comparison of data between experiments, which report responses in different units. The effect size is an easy measure of relative change between the control and the treatment group. When $L<0$, the effect of acidification in the treatment group is negative, and when $L>0$, the effect is positive. A response ratio of zero indicates that there is no effect and that the responses in the control and treatment group are the same. Since not all studies are equally precise, meaning that they are based on different numbers of replicates and variable standard deviations, the simple computation of the mean effect sizes is not recommended. Instead, a weighted mean is computed where more precise studies are given more weight.

This meta-analysis of the response ratios follows the approach of Hedges et al. (1999), with a few variations when weighting the effect sizes. A random-effects model was used where the assumption is made that the effect of ocean acidification varies between studies (Borenstein et al., 2010). For example, the effect size might differ between strains or it might result as significant if the response was measured more reliably or if the incubation time was longer. The randomeffects model accounts for this variation and includes the within-study variance $\left(v_{i}\right)$ as well as the between-study variance $\left(\sigma_{\lambda}^{2}\right)$ when calculating the mean effect for the response variables. Statistical significance for all effect sizes is displayed by the $95 \%$ confidence interval. The effect size is considered to be significant $(\alpha=0.05)$ when the confidence intervals do not overlap zero.

Traditionally, when studies report means, standard deviation, and sample size for both the control and treatment groups, a weighted meta-analysis is possible and the variance $\left(v_{i}\right)$ within the experiment $i$ can be calculated. Consequently, studies with a higher number of replicates and lower variance are weighted more heavily, which results in a more robust meta-analysis where the estimate of the effect size is more precise than in unweighted meta-analyses (Hedges and Olkin, 1985). Some of the data required for a weighted meta-analysis, however, were not available for some studies. In those cases, $v_{i}$ was estimated as the average of the computed variances from those experiments where $v_{i}$ was calculable. In this way it was possible to include all studies in the meta-analysis. Using the variance $v_{i}$ and the mean of the response ratio $L_{i}$ for each experiment $i$, Cochran's $Q$ (Cochran, 1954) was computed. Through use of $Q$, an estimate of the between-experiment variance $\left(\sigma_{\lambda}^{2}\right)$ was obtained (Hedges et al., 1999). The weighted mean of the log response 
ratio $\overline{L^{*}}$ is given by

$$
\overline{L^{*}}=\frac{\sum_{i=1}^{k} w_{i}^{*} L_{i}}{\sum_{i=1}^{k} w_{i}^{*}},
$$

where $k$ is the number of studies and $w_{i}=1 /\left(v_{i}+\sigma_{\lambda}^{2}\right)$.

Subsequently, the standard error of the weighted mean was estimated (see Eq. 7 in Hedges et al., 1999) and the confidence intervals were calculated. For all calculations Microsoft Excel $^{\circledR} 2008$ was used.

A normal distribution of the mean response ratio was assumed. As described in Hedges et al. (1999), this assumption can be made because the single response ratios are normally distributed as well.

\subsubsection{Identifying heterogeneity}

A test for heterogeneity in effect sizes was performed based on the $Q$ statistic. $Q$ approximately follows the chi-squared distribution with $k$ degrees of freedom. The null hypothesis of homogeneity among the effects of different experiments is rejected if $Q$ exceeds the $95 \%$ quantile of the distribution. Heterogeneity results in a positive estimate for the between-experiment variance $\sigma_{\lambda}^{2}$, which leads to a larger total variation, that is, the sum of the within- and betweenexperiment variance. Consequently, larger standard errors as well as wider confidence intervals for the effect size are computed from the weighted variances.

\section{Results}

Twenty-three studies were obtained from the literature; these are summarized in Tables 1 and 2. A total of 48 single experiments which met the above-mentioned criteria were extracted from these studies to be included in this metaanalysis.

The carbonate chemistry perturbation experiments examining responses of Emiliania huxleyi are depicted in Table 1. A total of 19 studies dealt with the responses of 14 different strains to ocean acidification. In most experiments, strains of Emiliania huxleyi showed reduced calcification rates with increased $p \mathrm{CO}_{2}$ concentrations (Barcelos e Ramos et al., 2010; De Bodt et al., 2010; Delille et al., 2005; Engel et al., 2005; Feng et al., 2008; Gao et al., 2009; Hoppe et al., 2011; Langer et al., 2009; Müller et al., 2010; Riebesell et al., 2000; Rokitta and Rost, 2012; Sciandra et al., 2003; Shi et al., 2009; Wuori, 2012; Zondervan et al., 2002). In other experiments some strains showed an optimum curve in response to increasing $p \mathrm{CO}_{2}$ (Bach et al., 2011; Langer et al., 2009), no significant response (Langer et al., 2009; Richier et al., 2011) or increased calcification rates (Fiorini et al., 2011; Iglesias-Rodriguez et al., 2008; Shi et al., 2009).

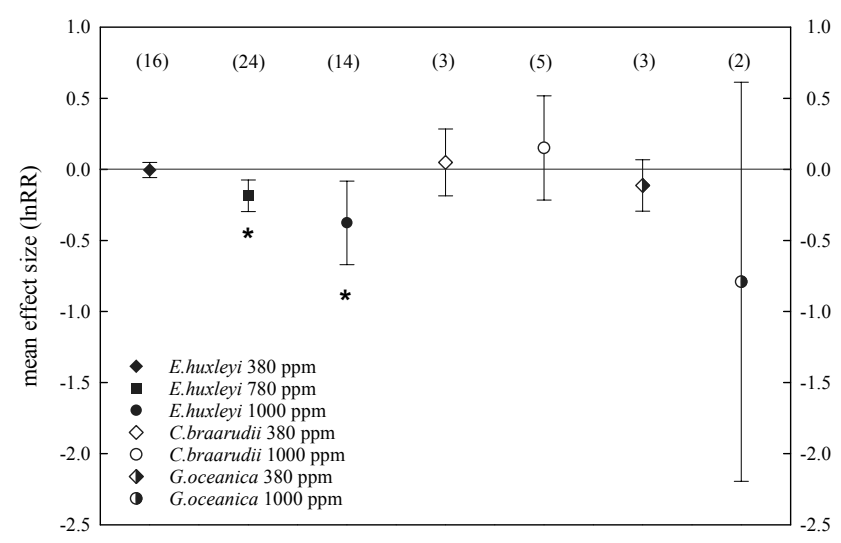

Figure 1. The effect of elevated $\mathrm{CO}_{2}$ concentrations on the calcification rates of three coccolithophore species: Emiliania huxleyi, Coccolithus braarudii and Gephyrocapsa oceanica (mean effect size and $95 \%$ confidence interval). Responses are relative to $280 \mathrm{ppm}$. * indicates a significant response, which is given when the confidence interval does not overlap zero. The number of experiments used to calculate mean effect sizes are shown in parentheses. The zero line indicates no effect.

Photosynthetic responses were more diverse. In six experiments no response was observed (De Bodt et al., 2010; Delille et al., 2005; Engel et al., 2005; Feng et al., 2008; Fiorini et al., 2011; Hoppe et al., 2011; Müller et al., 2010; Richier et al., 2011), while in another six experiments the POC production increased in response to elevated $p \mathrm{CO}_{2}$ (Barcelos e Ramos et al., 2010; Hoppe et al., 2011; IglesiasRodriguez et al., 2008; Riebesell et al., 2000; Rokitta and Rost, 2012; Shi et al., 2009; Wuori, 2012; Zondervan et al., 2002). Five experiments showed decreasing photosynthesis rates (Bach et al., 2011; Langer et al., 2009; Sciandra et al., 2003; Shi et al., 2009), whereas in three experiments an optimum curve was obtained (Gao et al., 2009; Langer et al., 2009).

The observed PIC / POC ratios are more homogeneous across experiments, with most of them decreasing with increased $p \mathrm{CO}_{2}$ (Bach et al., 2011; Barcelos e Ramos et al., 2010; De Bodt et al., 2010; Delille et al., 2005; Engel et al., 2005; Feng et al., 2008; Gao et al., 2009; Hoppe et al., 2011; Langer et al., 2009; Müller et al., 2010; Riebesell et al., 2000; Rokitta and Rost et al., 2012; Shi et al., 2009; Wuori, 2012; Zondervan et al., 2002). Only in four experiments did the PIC / POC ratio not change with increasing $p \mathrm{CO}_{2}$ (IglesiasRodriguez et al., 2008; Langer et al., 2009; Richier et al., 2011; Sciandra et al., 2003), and in one an increase was observed (Fiorini et al., 2011)

Experiments with other coccolithophore species also revealed varying responses (Table 2). Of the four experiments with Coccolithus braarudii, two observed a decrease in PIC production with increased $\mathrm{CO}_{2}$ levels (Krug et al., 2011; Müller et al., 2010), whereas one observed no response (Langer et al., 2006) and the other a slight increase in the 


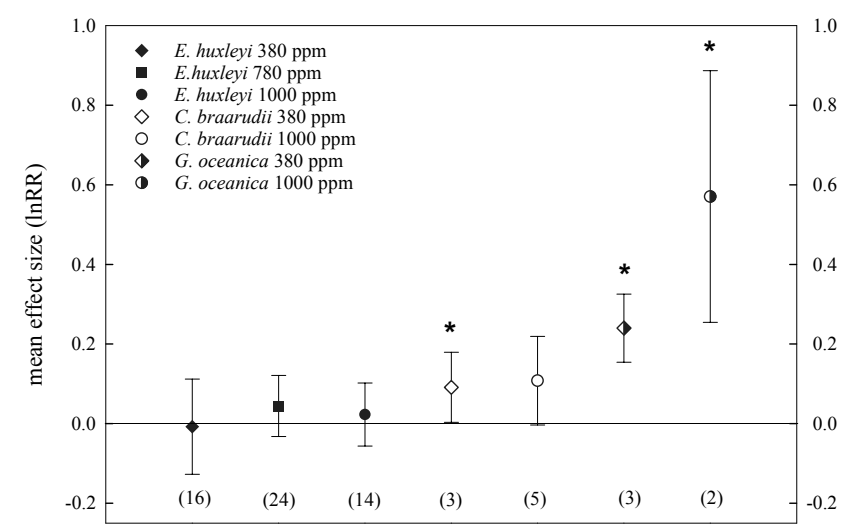

Figure 2. Mean effect of elevated $\mathrm{CO}_{2}$ concentrations (relative to $280 \mathrm{ppm}$ ) on the photosynthesis rates of three coccolithophores: Emiliania huxleyi, Coccolithus braarudii and Gephyrocapsa oceanica. Error bars denote the $95 \%$ confidence intervals. * indicates a significant response, which is given when the confidence interval does not overlap zero. The number of experiments included in the meta-analysis is shown in parentheses. The zero line indicates no effect.

calcification rate (Rickaby et al., 2010). The POC production rates varied just as much and increased in two experiments (Rickaby et al., 2010; Müller et al., 2010), while they did not change significantly in another experiment (Langer et al., 2006). In a fourth experiment a nonlinear response was observed (Krug et al., 2011).

In two experiments conducted with Gephyrocapsa oceanica, the calcification rates decreased (Riebesell et al., 2000) or did not change significantly (Rickaby et al., 2010) with increasing $p \mathrm{CO}_{2}$, whereas photosynthetic carbon fixation increased in one experiment (Riebesell et al., 2000) and showed an optimum curve in the other one (Rickaby et al., 2010). The PIC / POC ratio declined in both experiments.

In a fourth coccolithophore species, Calcidiscus leptoporus, the calcification response was nonlinear in two studies (Langer et al., 2006; Langer and Bode, 2011) and did not change in another (Fiorini et al., 2011), while the photosynthesis rate remained constant over the tested $\mathrm{CO}_{2}$ range (Fiorini et al., 2011; Langer et al., 2006; Langer and Bode, 2011).

\subsection{Effect of ocean acidification on calcification responses}

The meta-analysis of calcification responses to elevated $\mathrm{CO}_{2}$ concentrations revealed different results between the examined species (Fig. 1). Increasing $\mathrm{CO}_{2}$ concentrations from preindustrial to present-day levels had no significant effect on calcification in Emiliania huxleyi $(\operatorname{lnRR}=-0.004)$. In contrast, the effect of near-future $\mathrm{CO}_{2}$ concentrations under both the "business as usual" and the "worst case" scenario had significant negative effects on calcification in this species.
This negative effect was more pronounced at $1000 \mathrm{ppm}$ compared to $780 \mathrm{ppm}(780 \mathrm{ppm}: \operatorname{lnRR}=-0.19$, confidence inter$\mathrm{val}=-0.07$ to $-0.30 ; 1000 \mathrm{ppm}: \operatorname{lnRR}=-0.38$, confidence interval $=-0.08$ to -0.67 ).

In Gephyrocapsa oceanica an increase from preindustrial to present-day $\mathrm{CO}_{2}$ concentrations had a slightly negative but nonsignificant effect on calcification. Projected future ocean acidification had a negative mean effect on calcification greater than in Emiliania huxleyi, but it was not significant $(\operatorname{lnRR}=-0.79$, confidence interval $=0.61$ to -2.19$)$. In contrast, no significant effect of ocean acidification was detected in Coccolithus braarudii, where the mean effect sizes were slightly positive at both $p \mathrm{CO}_{2}$ concentrations. Significant heterogeneity was detected for all calcification responses.

\subsection{Effect of ocean acidification on photosynthetic responses}

A significant effect of ocean acidification on photosynthesis was observed in Gephyrocapsa oceanica for the present day as well as the high $\mathrm{CO}_{2}$ concentration, with the mean response at $1000 \mathrm{ppm}$ being more than twice as high $(\operatorname{lnRR}=0.57)$ as the mean response at $380 \mathrm{ppm}$ ( $\operatorname{lnRR}=0.24$, Fig. 2). For Coccolithus braarudii, a significant positive effect was observed at $380 \mathrm{ppm}$ and a similar but nonsignificant positive effect at $1000 \mathrm{ppm}$. No effect of ocean acidification on photosynthesis was observed for Emiliania huxleyi at 380 and $1000 \mathrm{ppm}$. Only at $780 \mathrm{ppm}$ was the mean effect size slightly positive $(\operatorname{lnRR}=0.044)$, but this effect was nonsignificant. A significant $Q$ statistic was calculated for all effect sizes.

\subsection{Effect of ocean acidification on PIC / POC responses}

The observed PIC / POC responses to an increased $\mathrm{CO}_{2}$ concentration are similar to those observed for the calcification responses (Fig. 3). For Emiliania huxleyi, there was a larger negative effect on PIC / POC at $1000 \mathrm{ppm}(\operatorname{lnRR}=-0.39)$ than at $780 \mathrm{ppm}(\operatorname{lnRR}=-0.22)$, but both responses were significantly negative. No effect was observed at present-day $\mathrm{CO}_{2}$ concentrations.

At both $\mathrm{CO}_{2}$ concentrations a small, nonsignificant negative effect of a similar magnitude $(380 \mathrm{ppm}: \operatorname{lnRR}=0.05$; $1000 \mathrm{ppm}: \operatorname{lnRR}=0.07$ ) was observed for Coccolithus braarudii. The strongest effect of ocean acidification on the PIC / POC ratio was observed for Gephyrocapsa oceanica. The mean effect size was significantly negative at both $p \mathrm{CO}_{2}$ levels, with the negative mean effect size at $1000 \mathrm{ppm}$ $(\operatorname{lnRR}=1.37)$ being more than 3 times lower than at $380 \mathrm{ppm}$ $(\ln R R=0.36)$. There was significant heterogeneity in all PIC / POC responses. 


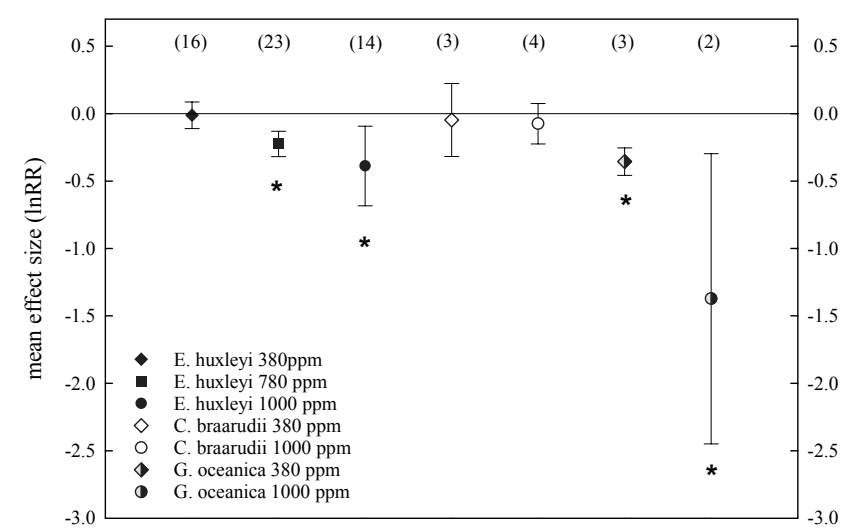

Figure 3. The effect of elevated $\mathrm{CO}_{2}$ concentrations on the inorganic to organic carbon ratio of three coccolithophore species: Emiliania huxleyi, Coccolithus braarudii and Gephyrocapsa oceanica (mean effect size and $95 \%$ confidence interval). Responses are relative to $280 \mathrm{ppm}$. * indicates a significant response, which is given when the confidence interval does not overlap zero. The number of experiments included in the meta-analysis is shown in parentheses. The zero line indicates no effect.

\subsection{Relationship between effect sizes and methodological factors}

For the three response variables (PIC, POC and PIC / POC) a further meta-analysis was conducted in order to test whether they varied between the two different carbonate chemistry manipulation methods (constant TA vs. constant DIC) used in the experiments.

This meta-analysis revealed that the mean effects of ocean acidification were not consistent between the two methods (Fig. 4). Keeping TA constant and changing DIC resulted in a more negative mean effect size for calcification and photosynthesis as compared to constant DIC and variable TA. However, the observed difference between the mean effect sizes for calcification was not significant $(p=0.07)$ and the overall effect of ocean acidification on calcification was negative, regardless of the manipulation method. In contrast, the mean effect sizes for photosynthesis differed substantially. While no significant effect was observed at constant TA, the effect size at constant DIC was significantly positive. There was significant difference between the mean effect sizes $(p=0.0001)$. The difference between the effect sizes for PIC / POC was only small. Here, ocean acidification had a slightly more negative effect when keeping DIC constant and changing TA. Both effect sizes were, however, significantly negative.

Interestingly, all experiments using Coccolithus braarudii and Gephyrocapsa oceanica manipulated the $p \mathrm{CO}_{2}$ in the culture medium by adding acid, i.e., changing TA while keeping DIC constant. Thus, all these experiments were included in the constant DIC treatments, while only experiments with Emiliania huxleyi were included in the constant

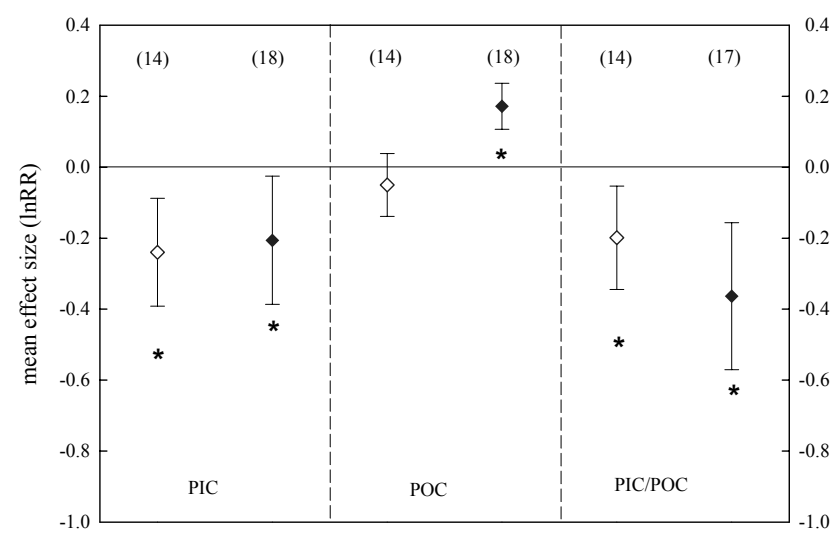

Figure 4. Comparison of effect sizes between the methods of carbonate chemistry manipulation. White diamonds symbolize treatments where total alkalinity (TA) was kept constant while dissolved inorganic carbon (DIC) changed. Black diamonds symbolize treatments where DIC was kept constant and TA varied. The number of experiments included in the meta-analysis are shown in parentheses. The mean effect size is significant when the $95 \%$ confidence interval does not overlap zero $(*)$.

TA treatments. In order to eliminate a possible bias due to the unequal distribution of coccolithophore species across carbonate chemistry manipulation methods, a separate metaanalysis was conducted. This analysis only included experiments of Emiliania huxleyi and determined the variation of effect sizes between carbonate chemistry manipulations (Fig. S1 in the Supplement). The results of this analysis were not significantly different from those obtained from the analysis performed on the full data set. A bias due to the unequal distribution of species between treatments can therefore be ruled out.

\section{Discussion}

The difference in variance between single studies is statistically described as heterogeneity. The term indicates that there is more variability in results than would be expected from the sampling distribution. Differences in the experimental setup, deviations in the measuring method and biological differences between the examined organisms can generally explain the existence of heterogeneity.

Heterogeneity in effect size was detected in all analyses in the present study. In retrospect, this finding justifies the use of a random-effects model in this meta-analysis. In contrast to the fixed-effects model, which only includes variance within the studies, the random-effects model accounts for the variance between and within single studies.

Our study revealed that heterogeneity in mean effect sizes is not due to different carbonate chemistry perturbation methods. The differences between TA and DIC manipulations in the carbonate chemistry were shown not to cause strong vari- 
ations in biological responses in coccolithophores - with a possible exception in photosynthetic responses. Another proposed explanation for the high difference in variance between studies could be the morphological and genetic differences of single coccolithophore strains. A high physiological variability has already been shown to exist in the coccolithophore Emiliania huxleyi (Iglesias-Rodriguez et al., 2006; Cubillos et al., 2007), with different strains and ecotypes exhibiting diverse responses to ocean acidification (Langer et al., 2009; Hoppe et al., 2011). Moreover, adaption processes of clones that are kept in culture over years could further result in variable responses in $\mathrm{CO}_{2}$ perturbation experiments (Ridgwell et al., 2009). Thus, a large part of the variance between the analyzed studies is most likely due to intra-species variability in coccolithophore species, especially in Emiliania huxleyi. A further reason for heterogeneity in mean effect size could be discrepancies in calculating the carbonate system from measured parameters. As mentioned earlier in this study, all components of the carbonate system can be calculated if two variables, e.g., $\mathrm{pH}$ and DIC, are known. A recently published study suggests that the $p \mathrm{CO}_{2}$ concentration measured in $\mathrm{CO}_{2}$ perturbation experiments differs strongly between calculations (up to $30 \%$ ) when the input parameters for these calculations are different (Hoppe et al., 2012). The authors state that some publications may not be comparable with each other, as $p \mathrm{CO}_{2}$ values might have been underestimated when they were calculated from TA and DIC, influencing the interpretation of coccolithophore responses. This finding also has implications for the present study, as some heterogeneity in mean effect size might be due to inconsistencies in calculating $p \mathrm{CO}_{2}$.

The aim of this study was to synthesize the available data of coccolithophores' biological responses to ocean acidification in order to more robustly estimate the actual effect of a lowered seawater $\mathrm{pH}$ on those calcifying organism. Despite known intra-specific variability, a negative effect of ocean acidification on calcification as well as on the cellular PIC / POC ratio was observed for the dominant and cosmopolitan species Emiliania huxleyi. Our results are in accordance with findings from a meta-analysis conducted by Findlay et al. (2011), who also identified a negative correlation between the cellular PIC / POC ratio in Emiliania huxleyi and the $p \mathrm{CO}_{2}$ concentration in the culture medium. Although some strains of E. huxleyi appear to be less sensitive to ocean acidification (Langer et al., 2009), the species shows a negative response towards reduced $p \mathrm{CO}_{2}$ levels in our meta-analysis, suggesting that strain-specific variations are small compared to the generally negative effect of ocean acidification on this species.

Calcification and PIC/POC in the coccolithophore Gephyrocapsa oceanica was even more negatively affected by future ocean acidification than in Emiliania huxleyi, indicating that $G$. oceanica is even more sensitive to changes in $p \mathrm{CO}_{2}$ and $\mathrm{pH}$. Although the meta-analysis with this species was based on only two studies and a significant effect on the

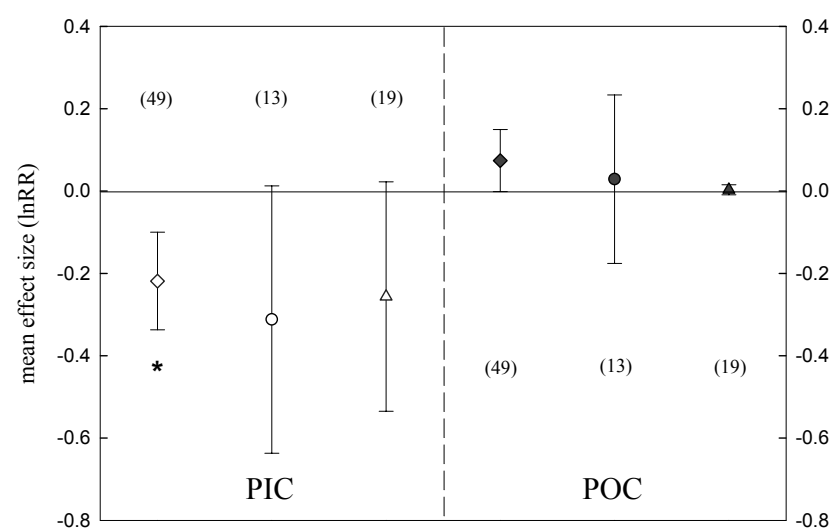

Figure 5. Comparison of effect sizes from PIC and POC analyses derived from the study by Kroeker et al. (2010, circles), Kroeker et al. (2013, triangles) and the present study (diamonds). Data from Kroeker et al. (2010 and 2013) were extracted directly out of the study with the help of the Web Plot Digitizer Software (www.arohatgi.info/WebPlotDigitizer/). The metaanalysis from the present study contains experiments of all coccolithophore species, including those of Calcidiscus leptoporus (see Table 2). Error bars denote the $95 \%$ confidence intervals. * indicates a significant response, which is given when the confidence interval does not overlap zero. The number of experiments included in the meta-analysis is shown in parentheses. The zero line indicates no effect.

calcification response was not observed, the mean effect sizes were even more negative than those observed for Emiliania huxleyi at $1000 \mathrm{ppm}$. We assume that the inclusion of more studies to the meta-analysis would likely decrease the confidence interval of the mean effect size, resulting in a significantly negative effect of ocean acidification on calcification in Gephyrocapsa oceanica. The strong negative effect of ocean acidification on the PIC / POC ratio in this species was not only due to the strong decrease in calcification but also a consequence of an increase in the photosynthesis rate with increasing $p \mathrm{CO}_{2}$. Apparently, this species profits more from high $p \mathrm{CO}_{2}$ levels during photosynthesis than the others. This might - at least for Gephyrocapsa oceanica - confirm the hypothesis that some coccolithophores might benefit from higher $\mathrm{CO}_{2}$ concentrations, since their rate of carbon fixation is below $\mathrm{CO}_{2}$ saturation at preindustrial $\mathrm{CO}_{2}$ levels (Riebesell et al., 2000; Riebesell, 2004; Rost et al., 2003; Nimer and Merrett, 1996). Higher $\mathrm{CO}_{2}$ concentrations in the water would thus allow them to more efficiently assimilate and fix carbon during photosynthesis and thus increase their photosynthesis rate (Rost et al., 2008). It is further suggested that an increase in the photosynthesis rate might buffer a possible negative effect of ocean acidification on calcification (Ries et al., 2009). If photosynthesis becomes more efficient and additional energy is provided due to enhanced photosynthetic activity, the building and maintenance of coccoliths could be facilitated. This hypothesis, however, was not confirmed by the present analysis, since the species that showed the most 
positive effect on photosynthesis, Gephyrocapsa oceanica, was also the one where the effect of ocean acidification on calcification was most negative.

For Coccolithus braarudii the results from the present study confirm the hypothesis that this species is insensitive to elevated $p \mathrm{CO}_{2}$ levels within the tested range (Langer et al., 2006). To some extent, it might even benefit from higher $\mathrm{CO}_{2}$ concentrations, as it exhibits a slightly positive photosynthesis response.

The results for the effect of ocean acidification on calcification gained by the present study are consistent with the observations by Kroeker et al. (2010, 2013; Fig. 5). These authors included responses of all coccolithophore species in one meta-analysis without distinguishing between species, and found a negative but nonsignificant effect of ocean acidification on calcification. They state that the absence of a significantly negative result might be due to the species-specific responses of coccolithophores, which can be confirmed by our study.

With some coccolithophore species being generally more sensitive with regard to ocean acidification than others, a replacement of sensitive strains by more tolerant strains of the same species or a shift in species composition is probable. It is not possible to assess whether a general decline in the abundance of coccolithophores with a replacement by other photoautotrophic organism is possible, as long as the role of calcification in coccolithophores is not completely understood. What implications a reduced calcium carbonate production has on the physiological performance and ecological fitness of coccolithophores therefore needs to be further evaluated. Considering that the more prevalent coccolithophore species appear to be vulnerable to ocean acidification, a local or global shift in the species composition or a replacement by other photoautotrophic organisms may occur and could affect higher trophic levels and ocean biogeochemical cycling.

Differences between TA and DIC manipulations were not the cause of variable calcification and PIC / POC responses between experiments, confirming earlier results by Kroeker et al. (2009), Findlay et al. (2011) and Hoppe et al. (2011) and following the reviews of Schulz et al. (2009) and Ridgwell et al. (2009). In contrast, mean effect sizes on photosynthetic rates were significantly different between the two manipulation methods. Whereas no effect of ocean acidification on photosynthesis was observed for the constant TA manipulations, the effect in the constant DIC manipulations was significantly positive. This finding is surprising, as the modifications of the carbonate system induced by the different manipulation methods are very similar, particularly in the range of carbonate chemistry changes projected to occur until the end of this century (Schulz et al., 2009). Although bubbling with $\mathrm{CO}_{2}$ more closely resembles predicted changes in the oceans carbonate chemistry, because dissolved inorganic carbon increases while total alkalinity remains unchanged, the modification of each carbonate system parameter $(\mathrm{pH}$, $\left[\mathrm{CO}_{2}\right],\left[\mathrm{CO}_{3}^{2-}\right]$ and $\Omega \mathrm{Ca}$ ) is rather similar. An exception is the concentration of $\mathrm{HCO}_{3}^{-}$, which increases slightly more in experiments where the $p \mathrm{CO}_{2}$ concentration is altered by $\mathrm{CO}_{2}$ bubbling (constant TA manipulation). As not only $\mathrm{CO}_{2}$ but also $\mathrm{HCO}_{3}^{-}$is known to be a carbon source for photosynthesis in most phytoplankton species (Riebesell, 2004), one could assume that the higher $\mathrm{HCO}_{3}^{-}$concentration in the constant TA manipulations was responsible for the observed difference in photosynthetic responses between manipulation methods. However, a higher rather than a lower photosynthesis rate would be expected in the constant TA manipulations compared to the constant DIC manipulations, as more inorganic carbon in the form of $\mathrm{HCO}_{3}^{-}$would be available for photosynthesis. Thus, it does not seem likely that the slight deviation in the $\mathrm{HCO}_{3}^{-}$concentration is responsible for the difference in mean effect sizes between manipulation methods. Nevertheless, discrepancies between the two methods of $\mathrm{CO}_{2}$ manipulation observed in the present study are consistent with findings of Kroeker et al. (2010). In their metaanalysis, a comparison of photosynthetic responses between manipulation methods also showed that keeping TA constant while increasing DIC caused a more negative effect. The deviation between the mean effect sizes was also significant in their study.

Although variable photosynthetic responses have been observed in different carbonate chemistry perturbation experiments, it remains to be clarified what causes these differences. To date, studies and reviews have mainly focused on revealing the reason for diverse calcification responses in coccolithophores (Ridgwell et al., 2009; Schulz et al., 2009). This is probably because ocean acidification is regarded to have a greater impact on calcification in those species than on photosynthesis. While the present study shows that this assumption holds true, a clear understanding of all physiological processes and their relevance for coccolithophore ecological fitness is necessary to realistically assess the influence of future ocean acidification on these organisms.

A limitation of the carbonate chemistry manipulation experiments included in this meta-analysis is the short duration of the experiments. As a result, they do not account for possible adaptation processes of coccolithophores that might occur over a longer time period, and only test for nonadaptive responses. A recent study investigated evolutionary adaptation in E. huxleyi in a long-term experiment (Lohbeck et al., 2012). In this study a population adapted to higher $p \mathrm{CO}_{2}$ levels showed significantly higher calcification rates than the control population. Although adaptation did not restore calcification rates under elevated $p \mathrm{CO}_{2}$ to those measured under ambient $p \mathrm{CO}_{2}$ levels, this observation highlights the possibility of adaptive evolution in coccolithophores. If species like Emiliania huxleyi and Gephyrocapsa oceanica can adapt to decreased $\mathrm{pH}$ levels, consequences for the whole ecosystem might be averted. It remains speculative, however, whether results from monocultural experiments can be extrapolated to the natural environment. This also has to be acknowledged when interpreting results of the present study. 
Generalizations from laboratory observations must be drawn with great care, and it has to be kept in mind that ocean acidification is not the only consequence of anthropogenic carbon emissions. Global warming and increased surface ocean stratification as well as changes in nutrient availability will further affect the physiological responses of marine organisms, including coccolithophores. Therefore, the effects of ocean acidification might differ when other potential stressors are included. Some studies have already examined the interactive effects of multiple stress factors on coccolithophore responses (e.g., Zondervan et al., 2002; Feng et al., 2008; De Bodt et al., 2010; Sett et al., 2014). However, more studies are required that analyze responses of coccolithophores to multiple stressors within the marine ecosystem in order to better quantify community and ecosystem responses to ocean acidification and global warming.

\section{The Supplement related to this article is available online at doi:10.5194/bg-12-1671-2015-supplement.}

The article processing charges for this open-access

publication have been covered by a Research

Centre of the Helmholtz Association.

Edited by: J. Middelburg

\section{References}

Armstrong, R. A., Lee, C., Hedges, J. I., Honjo, S., and Wakeham, S. G.: A new, mechanistic model for organic carbon fluxes in the ocean based on the quantitative association of POC with ballast minerals, Deep-Sea Res. Pt. II, 49, 219-236, 2002.

Bach, L. T., Riebesell, U., and Schulz, K.: Distinguishing between the effects of ocean acidification and ocean carbonation in the coccolithophore Emiliania huxleyi, Limnol. Oceanogr., 56, 2040-2050, 2011.

Barcelos e Ramos, J., Müller, M. N., and Riebesell, U.: Shortterm response of the coccolithophore Emiliania huxleyi to an abrupt change in seawater carbon dioxide concentrations, Biogeosciences, 7, 177-186, doi:10.5194/bg-7-177-2010, 2010.

Borenstein, M., Hedges, L. V., Higgins, J., and Rothstein, H. R.: A basic introduction to fixed-effect and random-effects models for meta-analysis, Res. Synth. Methods, 1, 97-111, 2010.

Brownlee, C. and Taylor, A.: Calcification in coccolithophores: A cellular perspective, in: Coccolithophores - From Molecular Processes to Global Impact, edited by: Thierstein, H. R. and Young, J. R., Springer, Germany, 31-49, 2004.

Cochran, W.: The contribution of estimates from different experiments, Biometrics, 10, 101-129, 1954.

Cubillos, J. C., Wright, S. W., Nash, G., de Salas, M. F., Griffiths, B., Tilbrook, B., Poisson, A., and Hallegraeff, G. M.: Calcification morphotypes of the coccolithophorid Emiliania huxleyi in the Southern Ocean: changes in 2001 to 2006 compared to historical data, Mar. Ecol.-Prog. Ser., 348, 47-54, 2007.
De Bodt, C., Van Oostende, N., Harlay, J., Sabbe, K., and Chou, L.: Individual and interacting effects of $p \mathrm{CO}_{2}$ and temperature on Emiliania huxleyi calcification: study of the calcite production, the coccolith morphology and the coccosphere size, Biogeosciences, 7, 1401-1412, doi:10.5194/bg-7-1401-2010, 2010.

Delille, B., Harlay, J., Zondervan, I., Jacquet, S., Chou, L., Wollast, R., Bellerby, R. G. J., Frankignoulle, M., Borges., A. V., Riebesell, U., and Gattuso, J. P.: Response of primary production and calcification to changes of $p \mathrm{CO}_{2}$ during experimental blooms of the coccolithophorid Emiliania huxleyi, Global Biogeochem. Cy., 19, 1-14, 2005.

Engel, A., Zondervan, I., Aerts, K., Beaufort, L., Benthien, A., Chou, L., Delille, B., Gattuso, J. P., Harlay, J., Heemann, C., Hoffmann, L., Jacquet, S., Nejstgaard, J., Pizay, M. D., RochelleNewall, E., Schneider, U., Terbrueggen, A., and Riebesell, U.:: Testing the direct effect of $\mathrm{CO}_{2}$ concentration on a bloom of the coccolithophorid Emiliania huxleyi in mesocosm experiments, Limnol. Oceanogr., 50, 493-507, 2005.

Feng, Y., Warner, M. E., Zhang, Y., Sun, J., Fu, F. X., Rose, J. M., and Hutchins, D. A.: Interactive effects of increased $p \mathrm{CO}_{2}$, temperature and irradiance on the marine coccolithophore Emiliania huxleyi (Prymnesiophyceae), Eur. J. Phycol., 43, 87-98, 2008.

Findlay, H. S., Calosi, P., and Crawfurd, K.: Determinants of the PIC:POC response in the coccolithophore Emiliania huxleyi under future ocean acidification scenarios, Limnol. Oceanogr., 56, 1168-1178, 2011.

Fiorini, S., Middelburg, J. J., and Gattuso, J. P.: Testing the effects of elevated $p \mathrm{CO}_{2}$ on coccolithophores (Prymnesiophyceae): comparison between haploid and diploid life stages, J. Phycol., 47, 1281-1291, 2011.

Gao, K., Ruan, Z., Villafañe, V. E., Gattuso, J. P., and Helbling, E. W.: Ocean acidification exacerbates the effect of UV radiation on the calcifying phytoplankter Emiliania huxleyi, Limnol. Oceanogr., 54, 1855-1862, 2009.

Hedges, L. V. and Olkin, I. (Eds.): Statistical Methods for MetaAnalysis, Academic Press, London, New York, 108-138, 1985.

Hedges, L. V., Gurevitch, J., and Curtis, P. S.: The meta-analysis of response ratios in experimental ecology, Ecology, 80, 11501156, 1999.

Hendriks, I. E., Duarte, C. M., and Álvarez, M.: Vulnerability of marine biodiversity to ocean acidification: A meta-analysis, Estuar. Coast. Shelf, 86, 157-164, 2010.

Hoppe, C. J. M., Langer, G., and Rost, B.: Emiliania huxleyi shows identical responses to elevated $p \mathrm{CO}_{2}$ in TA and DIC manipulations, J. Exp. Mar. Biol. Ecol., 406, 54-62, 2011.

Hoppe, C. J. M., Langer, G., Rokitta, S. D., Wolf-Gladrow, D. A., and Rost, B.: Implications of observed inconsistencies in carbonate chemistry measurements for ocean acidification studies, Biogeosciences, 9, 2401-2405, doi:10.5194/bg-9-2401-2012, 2012.

Iglesias-Rodriguez, M. D., Schofield, O. M., Batley, J., Medlin, L. K., and Hayes, P. K.: Intraspecific genetic diversity in the marine coccolithophore Emiliania huxleyi (Prymnesiophyceae): the use of microsatellite analysis in marine phytoplankton population studies, J. Phycol., 42, 526-536, 2006.

Iglesias-Rodriguez, M. D., Halloran, P. R., Rickaby, R. E., Hall, I. R., Colmenero-Hidalgo, E., Gittins, J. R., Green, D. R. H., Tyrrell, T., Gibbs, S. J., von Dassow, P., Rehm, E., Armbrust, E. V., and Boessenkool, K. P.: Phytoplankton Calcification in a High- $\mathrm{CO}_{2}$ World, Science, 320, 336-340, 2008. 
Jones, B. M., Iglesias-Rodriguez, M. D., Skipp, P. J., Edwards, R. J., Greaves, M. J., Young, J. R., Elderfield, H., and O'Connor, C. D.: Responses of the Emiliania huxleyi Proteome to Ocean Acidification, PLoS ONE, 8, e61868, doi:10.1371/journal.pone.0061868, 1-13, 2013.

Klaas, C. and Archer, D. E.: Association of sinking organic matter with various types of mineral ballast in the deep sea: Implications for the rain ratio, Global Biogeochem. Cy., 16, 63-1-63-14, 2002.

Kroeker, K. J., Kordas, R. L., Crim, R. N., and Singh, G. G.: Metaanalysis reveals negative yet variable effects of ocean acidification on marine organisms, Ecol. Lett., 13, 1419-1434, 2010.

Kroeker, K. J., Kordas, R. L., Crim, R., Hendriks, I. E., Ramajo, L., Singh, G. S., Duarte, C. M., and Gattuso, J. P.: Impacts of ocean acidification on marine organisms: quantifying sensitivities and interaction with warming, Glob. Change Biol., 19, 1884-1896, 2013.

Krug, S. A., Schulz, K. G., and Riebesell, U.: Effects of changes in carbonate chemistry speciation on Coccolithus braarudii: a discussion of coccolithophorid sensitivities, Biogeosciences, 8, 771-777, doi:10.5194/bg-8-771-2011, 2011.

Langer, G. and Bode, M.: $\mathrm{CO}_{2}$ mediation of adverse effects of seawater acidification in Calcidiscus leptoporus, Geochem. Geophy. Geosy., 12, 1-8, 2011.

Langer, G., Geisen, M., Baumann, K. H., Kläs, J., Riebesell, U., Thoms, S., and Young, J. R.: Species-specific responses of calcifying algae to changing seawater carbonate chemistry, Geochem. Geophy. Geosy., 7, 1-12, 2006.

Langer, G., Nehrke, G., Probert, I., Ly, J., and Ziveri, P.: Strain-specific responses of Emiliania huxleyi to changing seawater carbonate chemistry, Biogeosciences, 6, 2637-2646, doi:10.5194/bg-6-2637-2009, 2009.

Lefebvre, S. C., Benner, I., Stillman, J. H., Parker, A. E., Drake, M. K., Rossignol, P. E., Okimura, K. M., Komada, T., and Carpenter, E. J.: Nitrogen source and $p \mathrm{CO}_{2}$ synergistically affect carbon allocation, growth and morphology of the coccolithophore Emiliania huxleyi: potential implications of ocean acidification for the carbon cycle, Glob. Change Biol., 18, 493-503, 2012.

Lohbeck, K. T., Riebesell, U., and Reusch, T. B.: Adaptive evolution of a key phytoplankton species to ocean acidification, Nat. Geosci., 5, 346-351, 2012.

Müller, M. N., Schulz, K. G., and Riebesell, U.: Effects of long-term high $\mathrm{CO}_{2}$ exposure on two species of coccolithophores, Biogeosciences, 7, 1109-1116, doi:10.5194/bg-7-1109-2010, 2010.

Nakicenovic, N., Alcamo, J., Davis, G., De Vries, B., Fenhann, J., Gaffin, S., Gregory, K., Griibler, A., Jung, T. Y., Kram, T., Lebre, E., Rovere, L., Michaelis, L., Mori, S., Morita, T., Smith, S., Swart, R., Van Rooijen, S., Victor, N., and Dadi, Z.: Emission scenarios, A special report of Working Group III of the Intergovernmental Panel on Climate Change, Cambridge University Press, Cambridge, United Kingdom, 239-292, 2000.

Nimer, N. A. and Merrett, M. J.: The development of a $\mathrm{CO}_{2}$ concentrating mechanism in Emiliania huxleyi, New Phytol., 133, 383-389, 1996.

Richier, S., Fiorini, S., Kerros, M. E., Von Dassow, P., and Gattuso, J. P.: Response of the calcifying coccolithophore Emiliania huxleyi to low $p \mathrm{H} /$ high $p \mathrm{CO}_{2}$ : from physiology to molecular level, Mar. Biol., 158, 551-560, 2011.
Rickaby, R. E. M., Henderiks, J., and Young, J. N.: Perturbing phytoplankton: response and isotopic fractionation with changing carbonate chemistry in two coccolithophore species, Clim. Past, 6, 771-785, doi:10.5194/cp-6-771-2010, 2010.

Ridgwell, A., Schmidt, D. N., Turley, C., Brownlee, C., Maldonado, M. T., Tortell, P., and Young, J. R.: From laboratory manipulations to Earth system models: scaling calcification impacts of ocean acidification, Biogeosciences, 6, 2611-2623, doi:10.5194/bg-6-2611-2009, 2009.

Riebesell, U.: Effects of $\mathrm{CO}_{2}$ Enrichment on Marine Phytoplankton, J. Oceanogr., 60, 719-729, 2004.

Riebesell, U. and Tortell, P. D.: Effects of ocean acidification on pelagic organisms and ecosystems, in: Ocean Acidification, edited by: Gattuso, J. P. and Hansson, L., Oxford University Press, 99-121, 2011.

Riebesell, U., Zondervan, I., Rost, B., Tortell, P. D., Zeebe, R. E., and Morel, F. M.: Reduced calcification of marine plankton in response to increased atmospheric $\mathrm{CO}_{2}$, Nature, 407, 364-367, 2000.

Riebesell, U., Bellerby, R. G., Engel, A., Fabry, V. J., Hutchins, D. A., Reusch, T. B. H., Schulz, K. G., and Morel, F. M. M.: Comment on Phytoplankton Calcification in a High- $\mathrm{CO}_{2}$ World, Science, 322, 1466b, 2008.

Riebesell, U., Körtzinger, A., and Oschlies, A.: Sensitivities of marine carbon fluxes to ocean change, P. Natl. Acad. Sci. USA, 106, 20602-20609, 2009.

Ries, J. B., Cohen, A. L., and McCorkle, D. C.: Marine calcifiers exhibit mixed responses to $\mathrm{CO}_{2}$-induced ocean acidification, $\mathrm{Ge}$ ology, 37, 1131-1134, 2009.

Rokitta, S. D. and Rost, B.: Effects of $\mathrm{CO}_{2}$ and their modulation by light in the life-cycle stages of the coccolithophore Emiliania huxleyi, Limnol. Oceanogr., 57, 607-618, 2012.

Rost, B., Riebesell, U., Burkhardt, S., and Sültemeyer, D.: Carbon acquisition of bloom-forming marine phytoplankton, Limnol. Oceanogr., 48, 55-67, 2003.

Rost, B., Zondervan, I., and Wolf-Gladrow, D.: Sensitivity of phytoplankton to future changes in ocean carbonate chemistry: current knowledge, contradictions and research directions, Mar. Ecol.0Prog. Ser., 373, 227-237, 2008.

Sabine, C. L., Feely, R. A., Gruber, N., Key, R. M., Lee, K., Bullister, J. L., Wanninkhof, R., Wong, C. S., Wallace, D. W. R., Tilbrook, B., Millero, F. J., Peng, T. H., Kozyr, A., Ono, T., and Rios, A. F.: The oceanic sink for anthropogenic $\mathrm{CO}_{2}$, Science, 305, 367-371, 2004.

Sciandra, A., Harlay, J., Lefèvre, D., Lemée, R., Rimmelin, P., Denis, M., and Gattuso, J. P.: Response of coccolithophorid Emiliania huxleyi to elevated partial pressure of $\mathrm{CO}_{2}$ under nitrogen limitation, Mar. Ecol.-Prog. Ser., 261, 111-122, 2003.

Sett, S., Bach, L. T., Schulz, K. G., Koch-Klavsen, S., Lebrato, M., and Riebesell, U.: Temperature modulates coccolithophorid sensitivity of growth, photosynthesis and calcification to increasing seawater $\mathrm{pCO}_{2}, \mathrm{PLoS}$ ONE, 9, e88308, doi:10.1371/journal.pone.0088308, 2014.

Shi, D., Xu, Y., and Morel, F. M. M.: Effects of the $\mathrm{pH} / p \mathrm{CO}_{2}$ control method on medium chemistry and phytoplankton growth, Biogeosciences, 6, 1199-1207, doi:10.5194/bg-6-1199-2009, 2009.

Shutler, J. D., Grant, M. G., Miller, P. I., Rushton, E., and Anderson, K.: Coccolithophore bloom detection in the northeast Atlantic 
using SeaWiFS: Algorithm description, application and sensitivity analysis, Remote Sens. Environ., 114, 1008-1016, 2010.

Wuori, T.: Effects of elevated $p \mathrm{CO}_{2}$ on the physiology of Emiliania huxleyi, M.Sc. Thesis, Western Washington University, USA, 97 pp., 2012.

Ziveri, P., de Bernardi, B., Baumann, K. H., Stoll, H. M., and Mortyn, P. G.: Sinking of coccolith carbonate and potential contribution to organic carbon ballasting in the deep ocean, DeepSea Res. Pt. II, 54, 659-675, 2007.
Zondervan, I., Rost, B., and Riebesell, U.: Effect of $\mathrm{CO}_{2}$ concentration on the PIC/POC ratio in the coccolithophore Emiliania huxleyi grown under light-limiting conditions and different daylengths, J. Exp. Mar. Biol. Ecol., 272, 55-70, 2002. 